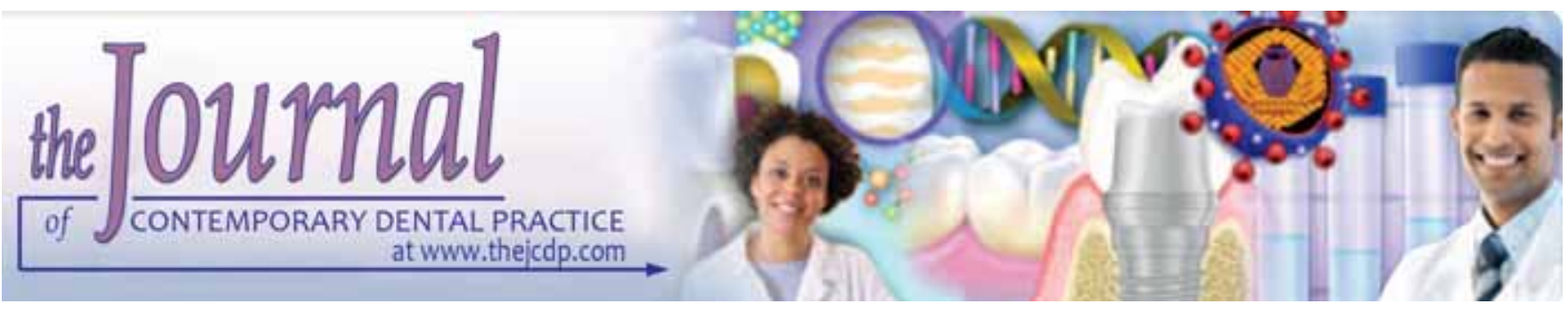

\title{
Surface Morphological Changes in Human Enamel Following Bleaching: An in vitro Scanning Electron Microscopic Study
}

AG Rajesh, LM Ranganath, KS Prem Kumar, B Sunil Rao

\begin{abstract}
Objective: The purpose of this study was to evaluate, using scanning electron microscopy (SEM), the morphological and structural changes of the enamel induced by three bleaching agents namely old Mclnnes solution, modified McInnes solution and $10 \%$ carbamide peroxide gel at different time intervals.

Materials and methods: Fifteen freshly extracted noncarious human central incisors with intact enamel surface were selected. The teeth were sectioned at the cementoenamel junction separating the crown portion from the root using a diamond separating disk. Following this, the samples were subjected to three different bleaching agents: G roup 1: Old McInnes solution, group 2: modified McInnes solution and group 3: 10\% carbamide peroxide for a period of 15, 30 and 60 minutes, 24 and 30 hours time interval. The sample stubs were subjected to scanning electron microscope and were photographed at 2000 and 10,000 magnifications.
\end{abstract}

Conclusion: The present study revealed no indication of either etching or significant change in surface morphology of enamel when evaluated under scanning electron microscope after 6 weeks treatment with various bleaching agents.

Clinical significance: Morphological alterations in bleached enamel are both concentration and time dependent.

Keywords: Dental enamel, Mclnness solution, Peroxides.

How to cite this article: Rajesh AG, Ranganath LM, Kumar KSP, Rao BS. Surface Morphological Changes in Human Enamel Following Bleaching: An in vitro Scanning Electron Microscopic Study. J Contemp Dent Pract 2012;13(3):405-415.

Source of support: Nil

Conflict of interest: None declared

\section{INTRODUCTION}

Esthetics, by definition is the science of beauty, it is derived from the greek word 'perception' which deals with beauty as an art.

In the modern civilized cosmetically conscious world well-contoured and well-aligned white teeth, set the standard for beauty. Such teeth are not only considered attractive, but also indicative of nutritional health, self-esteem, hygienic pride and economic status.

Currently there are several methods available to treat discolored dentitions, such as laminates, porcelain jacket crowns and bleaching methods.

B leaching as a treatment modality, continues to hold its century old place as the simplest, most common, least invasive and least expensive means to lighten discolored teeth.

Hydrochloric acid and hydrogen peroxide ${ }^{1,2}$ have been used alone and in combination, in a variety of treatment techniques to remove stains from vital teeth. Hydrochloric acid was reportedly the first of the two chemical agents used to remove intrinsic dental stains from vital teeth.

Heat was applied on the assumption that the bleaching agents would penetrate deeper into the enamel and dentin. ${ }^{3}$ But there was concern about the effect of hydrogen peroxide and heat on the pulp. ${ }^{4}$

The M clnnes bleaching agent, which was introduced, did not require heat to enhance its effect, but, the hydrochloric acid had deleterious effects ${ }^{5,6}$ on the enamel structure resulting in al teration of the tooth contour. ${ }^{7}$

The M clnnes bleaching agent was modified by replacing the hydrochloric acid with $20 \%$ sodium hydroxide. Reports ${ }^{8,9}$ suggested that the modified/new Mclnnes bleaching agent was much more effective and had less deleterious effects on the enamel. ${ }^{10}$

Recently, home-bleaching methods have been introduced to treat discolored teeth. This basically consists of $10 \%$ carbamide peroxide in a custom fitted mouth tray. $V$ arious studies $^{11}$ have suggested that $10 \%$ carbamide peroxide has less deleterious effects on teeth and surrounding tissues.

This in vitro study was conducted to compare enamel surface morphologic changes induced by three bleaching agents namely old M clnnes, new/modified M clnnes solution, and $10 \%$ carbamide peroxide gel, at different time intervals under scanning electron microscope. 


\section{MATERIALS AND METHODS}

Fifteen freshly extracted human incisors for periodontal reasons, noncarious with intact enamel surface were collected from the Department of Oral Surgery SDM D ental College, Dharwad. Teeth were stored in normal saline at room temperature till the experiments were performed.

The armamentarium used in the present study:

1. Mouth mirror and probe.

2. Saline solution.

3. M icromotor handpiece.

4. Diamond coated separating disk.

5. Polishing paste.

6. Polishing rubber cup.

7. Sterile sealed bottles for storage.

8. Teflon tape.

9. Scanning electron microscope (JOEL-JRC 1100CE).

10. Gold sputter coater (JOEL-JSM 840A).

\section{Bleaching Materials Tested}

\section{Old M clnnes}

\section{New M clnnes}

3. Nupro Gold Tooth whitening system

\section{Sectioning Procedures}

The labial surface of the disinfected teeth were polished using a polishing paste with the help of a rubber cup and a slow speed handpiece.

The teeth were sectioned at the cementoenamel junction separating the crown from the root using a diamond separating disk fitted to a micromotor handpiece.

\section{Surface Treatment}

Prior to the actual bleaching procedure, left half of the cleaned crown samples were covered with teflon tape, longitudinally, while the right half was subjected to the bleaching agents.

Fifteen samples were divided in to three groups of five specimens each:

Group 1: The five specimens were subjected to old M cl nnes bleaching solutions for a period of 15,30 and 60 minutes time intervals.

Group II: The five specimens were subjected to new M clnnes bleaching solution for a period of 15, 30, 60 minutes, 24 and 30 hours time intervals.
Group III: Five specimens were subjected to $10 \%$ carbamide peroxide gel for $15,30,60$ minutes, 24 and 30 hours time interval.

A fter treatment the specimens were washed with normal saline and stored in sterile sealed bottles.

\section{Sample Preparation for Scanning Electron Microscopy}

The samples were mounted on aluminum stubs with double sided scotch tape silver paste applied to make them conductive. The stubs were placed in a vacuum chamber of the ion sputter, gold coating unit (model J OEL-J FC-1100E). A thin layer (approximately 200A) of gold under vacuum evaporated on to the surface of a tooth.

The gold layer was necessary to prevent charge buildup on the tooth surface during electron bombardment.

The sample stubs was inserted in (model JOEL -ISM $10 \mathrm{~A}$ ) to vacuum chamber of scanning electron microscope and were photographed at 1000 and 10,000 magnifications.

\section{RESULTS}

The photomicrographs obtained from the scanning electron microscopy after treatment was examined for mild, moderate and severe al terations.

In all cases, the left side control (unbleached surface) presented a similar appearance. The surface showed no alteration or changes, indicating that the solution did not penetrate or seep under the teflon covered surface.

The surface changes were noticeable when the scanning electron microscope was moved across the border from the untouched control side of the specimen to the exposed tested surface.

\section{DISCUSSION}

$M$ any dental procedures are performed empirically and without knowledge of what their biological effects may be. This lack of understanding may give rise to unpredictable results, if and when subsequent treatment is required.

This in vitro study, evaluated the effect of three bleaching agents namely-old M clnnes solution, new $\mathrm{M} \mathrm{clnnes} \mathrm{solution} \mathrm{and} \mathrm{10 \%} \mathrm{carbamide} \mathrm{peroxide} \mathrm{gel} \mathrm{(N} \mathrm{upro}$ Gold tooth whitening system) on enamel surface, observed under scanning electron microscope at different time intervals, showed alterations in surface morphology of enamel ranging from mild-to-moderate (Table 1 ) and severe in case of old $\mathrm{M}$ clnnes bleaching solution.

The surface changes caused by new $M$ clnnes solution (Table 2) and 10\% carbamide peroxide gel (Table 3), consisted primarily of minor alterations, such as an apparent increase in surface porosities, grooves, deepening of fissure 
Surface Morphological Changes in Human Enamel Following Bleaching: An in vitro Scanning Electron Microscopic Study

\begin{tabular}{lccc}
\multicolumn{4}{c}{ Table 1: Bleaching agent-old Mclnnes solution } \\
\hline Time interval & Mild & Moderate & Severe \\
\hline 15 minutes & & ++ & \\
30 minutes & & + \\
60 minutes & & + \\
\hline
\end{tabular}

Table 2: Bleaching agent-new Mclnnes solution

\begin{tabular}{lccc} 
Time interval & Mild & Moderate & Severe \\
\hline 15 minutes & + & \\
30 minutes & + & \\
60 minutes & + & + \\
24 hours & & + \\
30 hours & & \\
\hline
\end{tabular}

Table 3: Bleaching agent-10\% carbamide peroxide

\begin{tabular}{|c|c|c|c|}
\hline Time interval & Mild & Moderate & Severe \\
\hline 15 minutes & + & & \\
\hline 30 minutes & + & & \\
\hline 60 minutes & + & & \\
\hline 24 hours & & + & \\
\hline 30 hours & & + & \\
\hline
\end{tabular}

Mild: Moderate alternations of aprismatic layer in the enamel surface. Moderate+: Increased porosity, deep fissures and opening of enamel prism.

Moderate ++: Hollowing of enamel prism centers with relatively intact prism peripheries, similar to acid etching pattern.

Severe: Entire enamel surface is eroded; the scalloped/ pitted dental surface with opening of dentinal tubules is seen.

and opening of enamel prisms. ${ }^{12,13}$ These changes appeared to be time related, i.e. longer the exposure of the enamel to the bleaching solutions, more marked were the effect. ${ }^{14}$

Bitter $\mathrm{NC}^{15}$ in a scanning electron microscope study of long-term effect of bleaching agents on the enamel surface in vivo, concluded that bleaching over a long time may be associated with increased enamel and altered enamel could also be vulnerable to subsequent staining.

Seghi and D enry ${ }^{16}$ reported an increase of up to $40 \%$ in the fracture susceptibility of enamel, dentin and cementum after bleaching. This present study cannot support these findings because of the limitations of SEM .

M clnnes, in 1966, advocated a solution of five parts $30 \%$ hydrogen peroxide, five parts $36 \%$ hydrochloric acid and one part anesthetic ether (old M clnnes bleaching solution) to be applied topically on the tooth surface for 15 to 30 minutes, to treat fluorosed enamel. ${ }^{17}$

In this study, the enamel surface was exposed to old $\mathrm{M} \mathrm{clnnes}$ bleaching solution, at 15, 30 and 60 minutes time intervals.

In case of old M clnnes bleaching agent, a 15 minutes exposure resulted in a typical acid etched surface pattern of the enamel where as a 30 and 60 minutes exposure resulted in severe changes, wherein the entire enamel surface was eroded (Figs 1 to 9).
The deleterious effect on the enamel surface pattern of the enamel, where as a 30 and 60 minutes exposure resulted in severe changes, wherein the entire enamel surface was eroded (Graph 1).

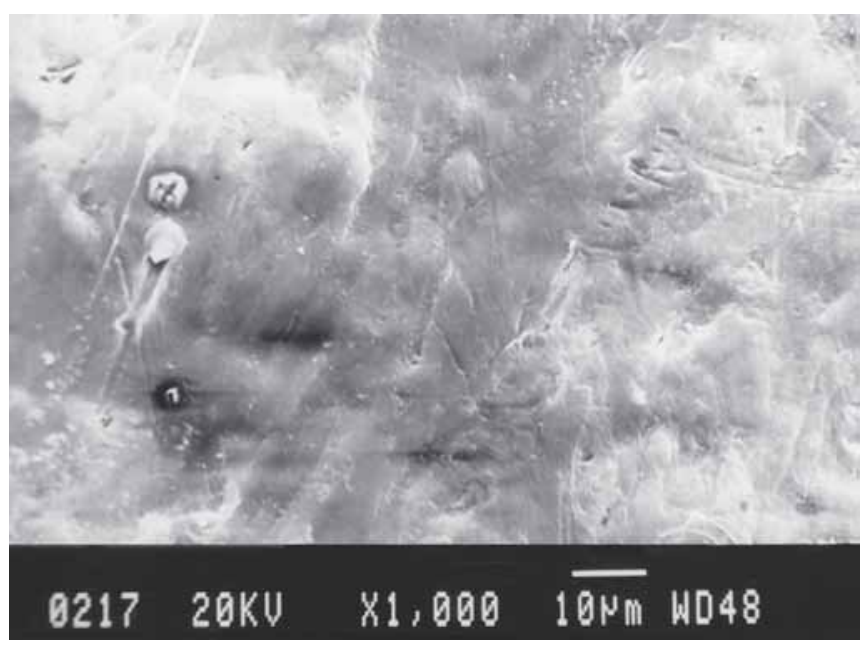

Fig. 1: Tooth surface: Control group I (×1000 magnification)

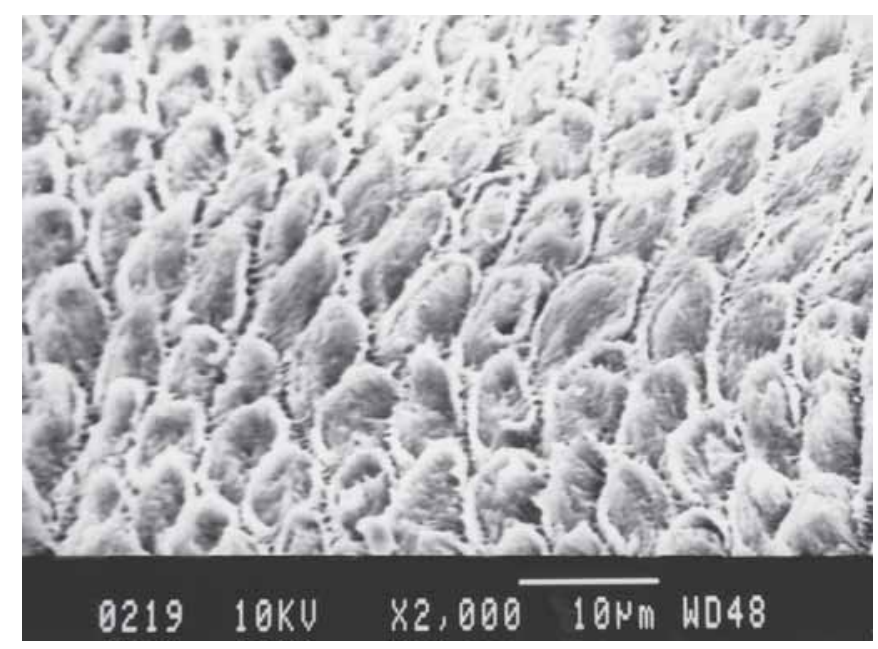

Fig. 2: Tooth surface exposed to old Mclnnes bleaching agent for 15 minutes. A typical acid etched pattern is seen ( $\times 2000$ magnification)

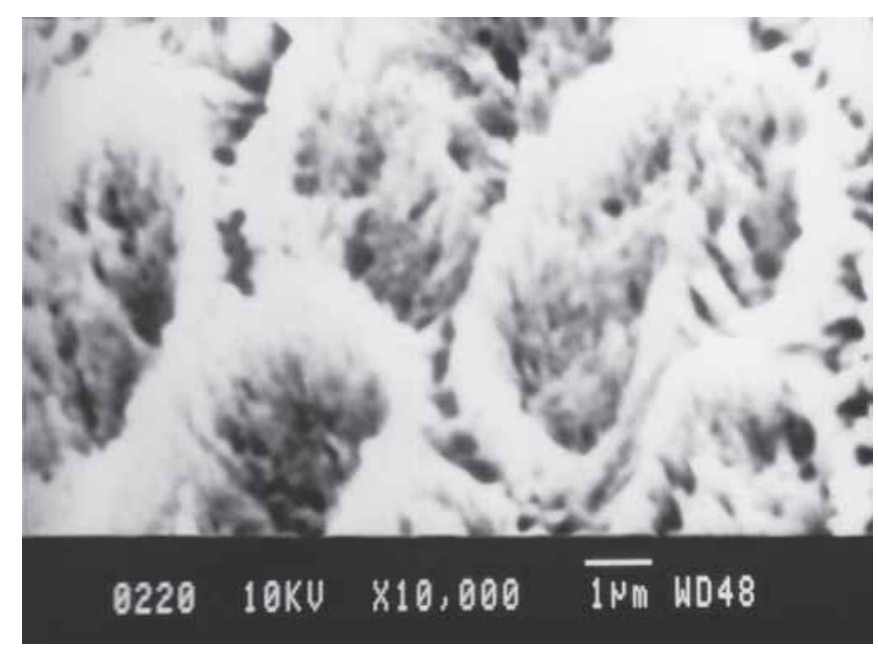

Fig. 3: Tooth surface exposed to Old Mclnnes bleaching agent for 15 minutes $(\times 10,000$ magnification) 


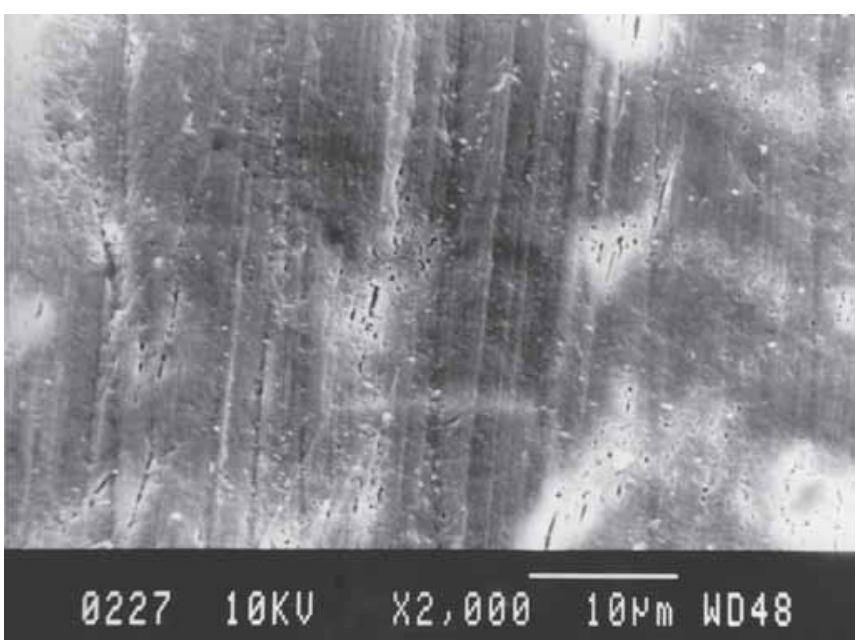

Fig. 4: Tooth surface control group I (×2000 magnification)

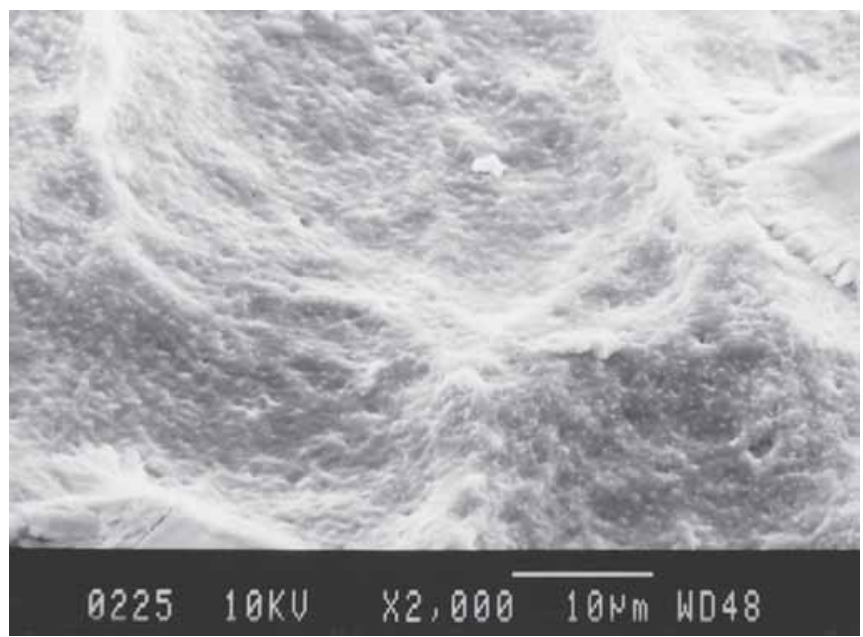

Fig. 5: Tooth surface exposed to old Mclnnes bleaching agent for 30 minutes. Scalloped dentinal surface is seen ( $\times 2000$ magnification)

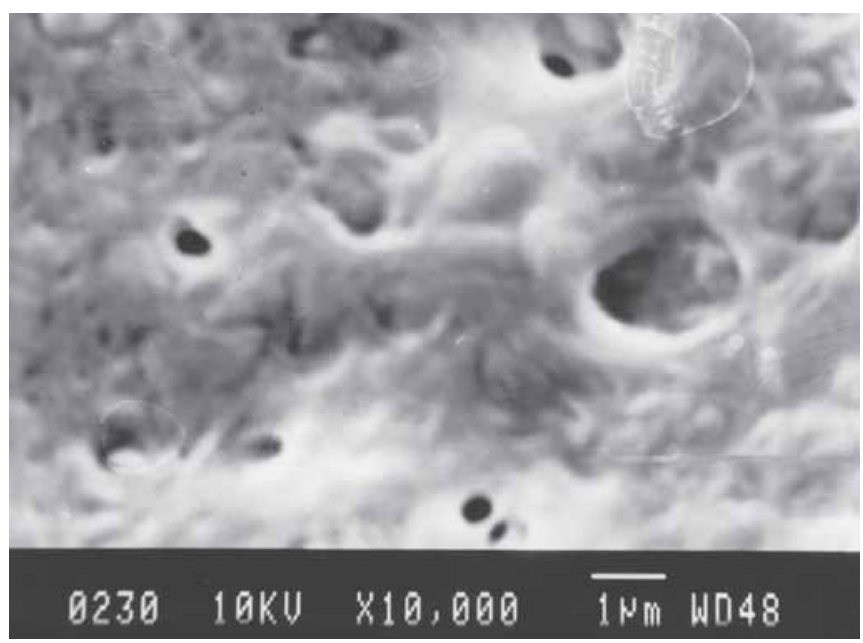

Fig. 6: Tooth surface exposed to old Mclnnes bleaching agent for 30 minutes. Opening of dentinal tubules seen $(\times 10,000$ magnification)

The deleterious effect on the enamel surface in mainly attributed to the $30 \%$ hydrochloric acid content of the old $\mathrm{M}$ cl nnes bleaching solution. The observations of this present study with regard to hydrochloric acid is well correlated to,

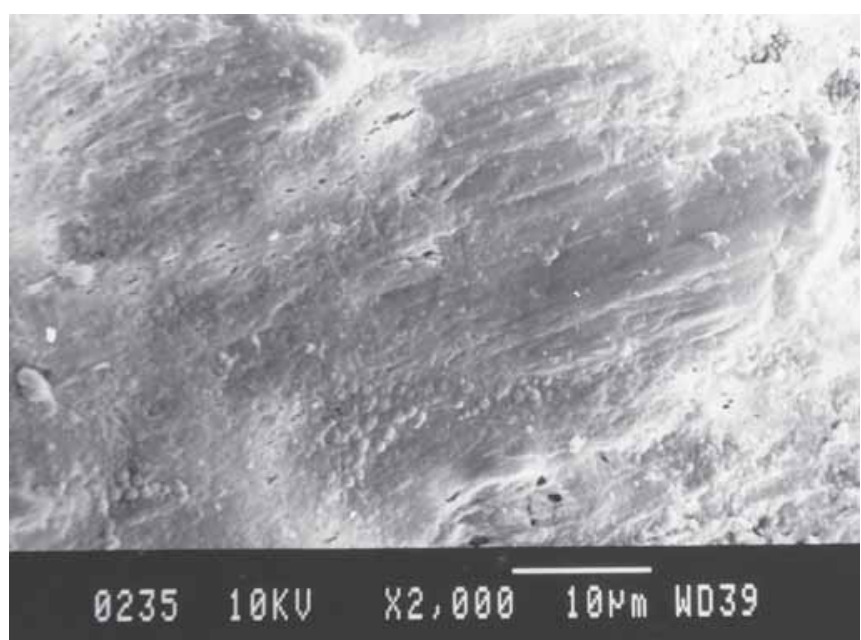

Fig. 7: Tooth surface control group I (×2000 magnification)

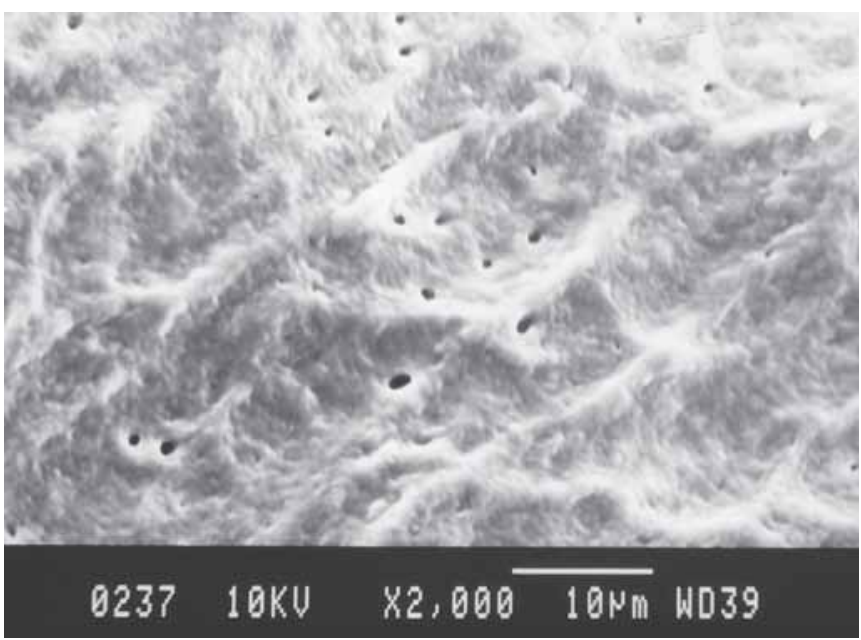

Fig. 8: Tooth surface exposed to old Mclnnes bleaching agent for 60 minutes. Scalloped dentinal surface with opening of dentinal tubules seen ( $\times 2000$ magnification)

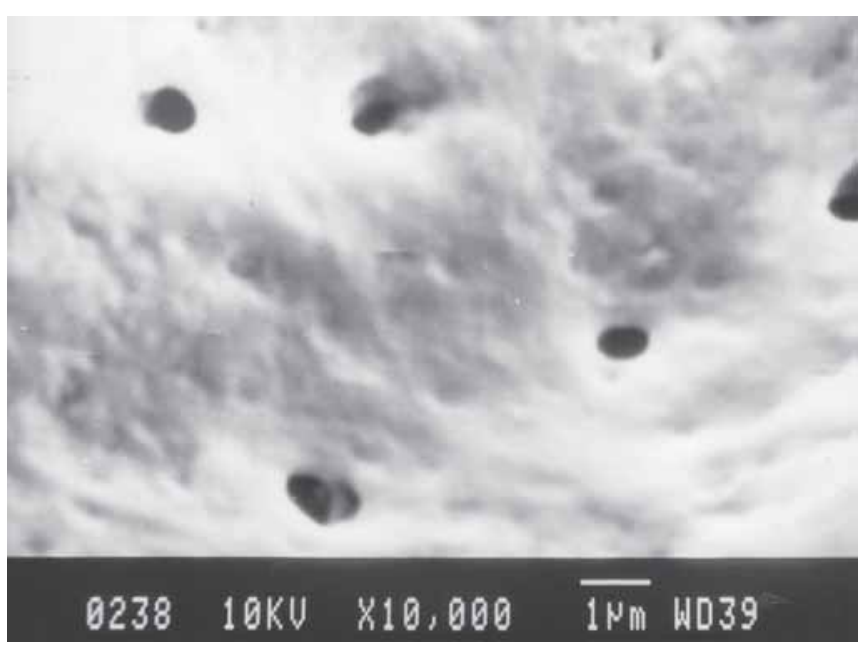

Fig. 9: Tooth surface exposed to old Mclnnes bleaching agent for 60 minutes. Opening of dentinal tubules seen ( $\times 10,000$ magnification)

McEnvoy findings that hydrochloric acid used in concentrations ranging from 18 to $30 \%$ acts by decalcifying enamel along with the stain. ${ }^{18}$ According to Griffin RE et al the decalcifying action of hydrochloric acid when used 


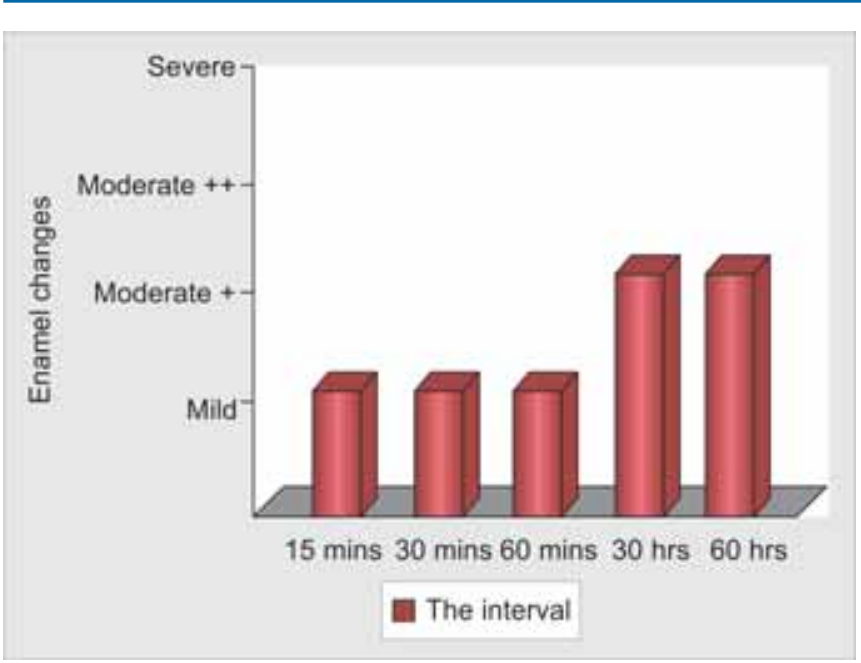

Graph 1: Old Mclnnes solution

alone or as part of solutions containing hydrogen peroxide has been shown to cause considerable etching after 2 minutes applications in vitro. ${ }^{19}$

M cEnvoy noted that hydrochloric acid decalcifies the superficial $16 \%$ of the enamel surface and is used to remove stains physically.

The hydrochloric acid is not selective in its mode of action and this could be the reason for the extensive surface morphologic changes when exposed to old Mclnnes bleaching solution.

Chen $\mathrm{H}$ ua ji et al ${ }^{20}$ modified the $\mathrm{M}$ clnnes solution by replacing hydrochloric acid with $20 \% \mathrm{NaOH}$ solution to overcome the deleterious effect of hydrochloric acid. The modified new M clnnes bleaching solution consisted of $30 \%$ hydrogen peroxide and $20 \% \mathrm{NaOH}$ in a $1: 1$ ratio. The oxidizing ability and releasing of oxygen from hydrogen peroxide is stronger in a basic solution than acidic solution. They suggested that this mixture was effective in bleaching of stains that respond to hydrogen peroxide. Their study concluded that the decomposition of $30 \%$ hydrogen peroxide in a $20 \% \mathrm{NaOH}$ solution was faster and more violent than in old $\mathrm{M}$ clnnes solution. ${ }^{21}$

In the present study, the enamel surface was exposed to modified M clnnes bleaching agents for a longer time intervals of 15,30 minutes, 24 and 30 hours respectively (Graph 2).

The modified $\mathrm{MCl}$ nnes bleaching solution resulted in mild-to-moderate enamel, changes when exposed at different time intervals. Mild changes were observed up to 1 hour, where there was alteration of aprismatic layers of enamel surface, whereas exposure of up to 24 and 30 hours resulted in moderate changes consisting of increased porosities, deepening of fissures and opening of enamel prisms (Figs 10 to 21).

Our observations regarding the new $\mathrm{M} \mathrm{Cl}$ nnes bleaching solution are well correlated with the findings of Ji Chen et al who suggested, that new $\mathrm{M}$ cl nnes had lesser deleterious effects on the enamel surface. ${ }^{22}$

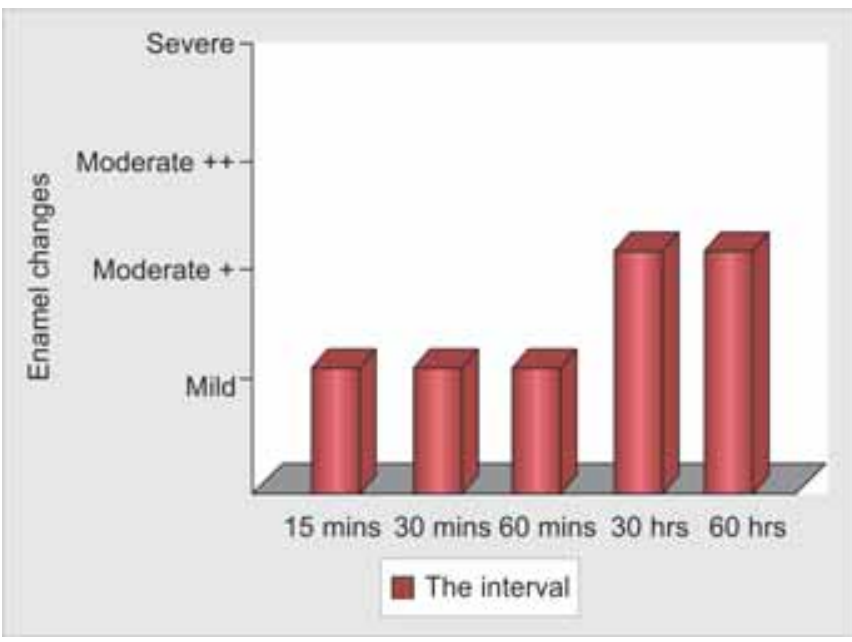

Graph 2: New Mclnnes solution

According to M CEnvoy AS hydrogen peroxide being a strong oxidizing agent, the process by which it works within the enamel or dentin is most likely an oxidization process ${ }^{23,24}$ which removes the stain by its oxygen releasing, mechanical cleaning action. Hydrogen peroxide is more selective than hydrochloric acid in stain removal; this mechanism of action makes hydrogen peroxide method a safe and conservative approach.

Studies have shown that teeth placed in labeled hydrogen peroxide shows increased permeability. ${ }^{25,26}$ This has been attributed to the low molecular weight of hydrogen peroxide $(30 \mathrm{~g} / \mathrm{mol}$ ) and its ability to denature proteins, thereby increasing the movement of ions through the tooth. ${ }^{27}$

Haywood BV and Heymann's clinical observations through 75 years of bleaching with $35 \%$ of hydrogen peroxide bleaching agent have never revealed any detrimental effect on enamel surface texture. ${ }^{28}$

The manufacturers of N upro Gold tooth whitening system ( $10 \%$ carbamide peroxide gel) have recommended a day time schedule - exposure to the agent for at least 2 hours, and a night time schedule throughout the night, until the desired result is obtained.

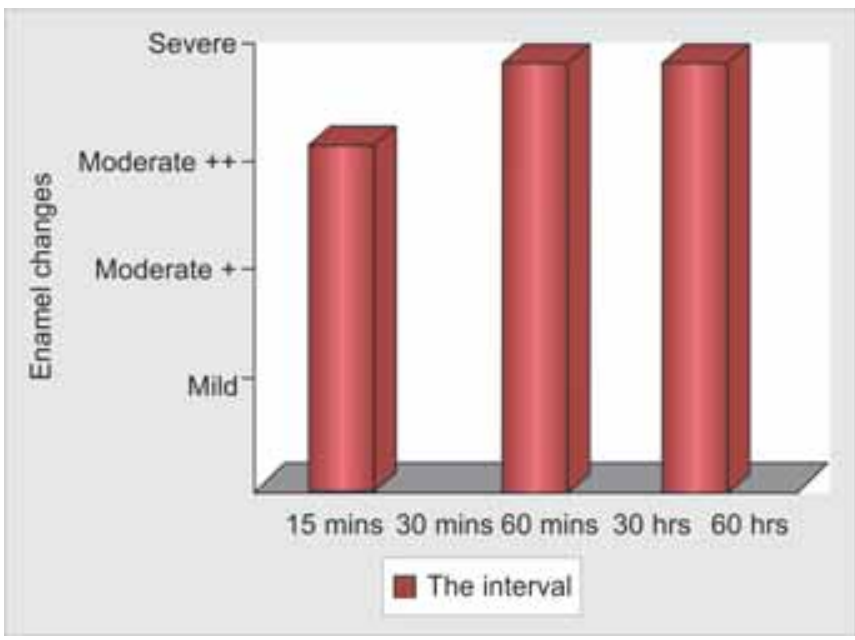

Graph 3: $10 \%$ carbamide peroxide gel 


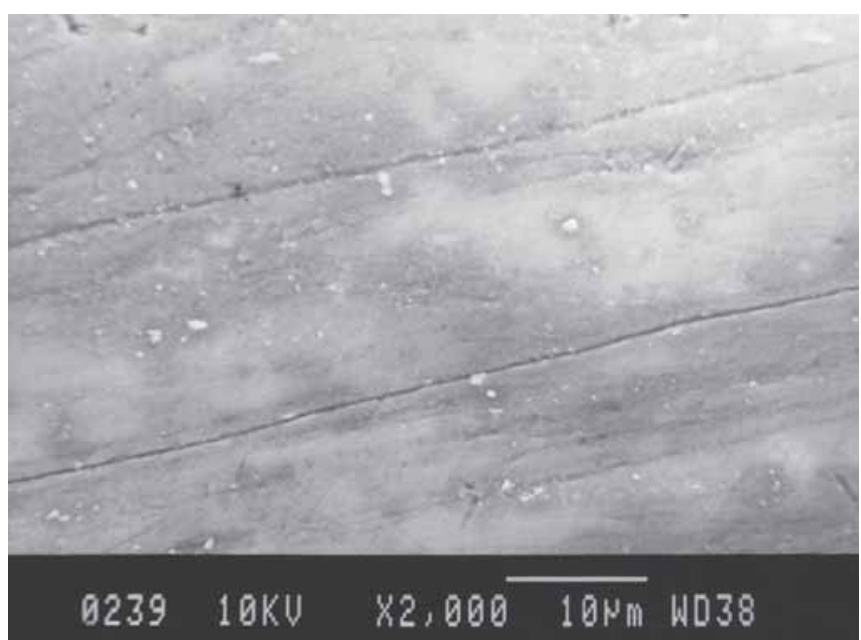

Fig. 10: Tooth surface control group II (×2000 magnification)

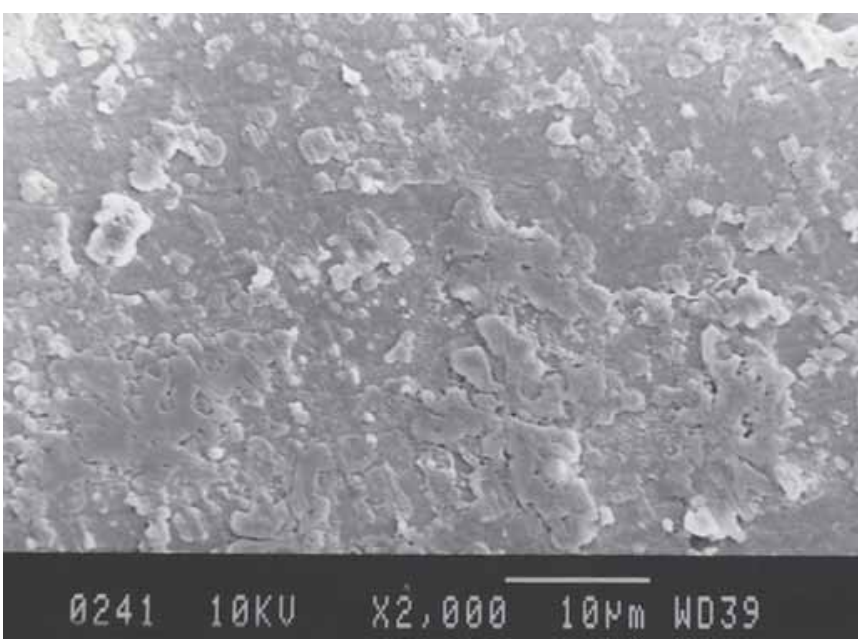

Fig. 11: Tooth surface exposed to new Mclnnes bleaching agent for 15 minutes ( $\times 2000$ magnification)

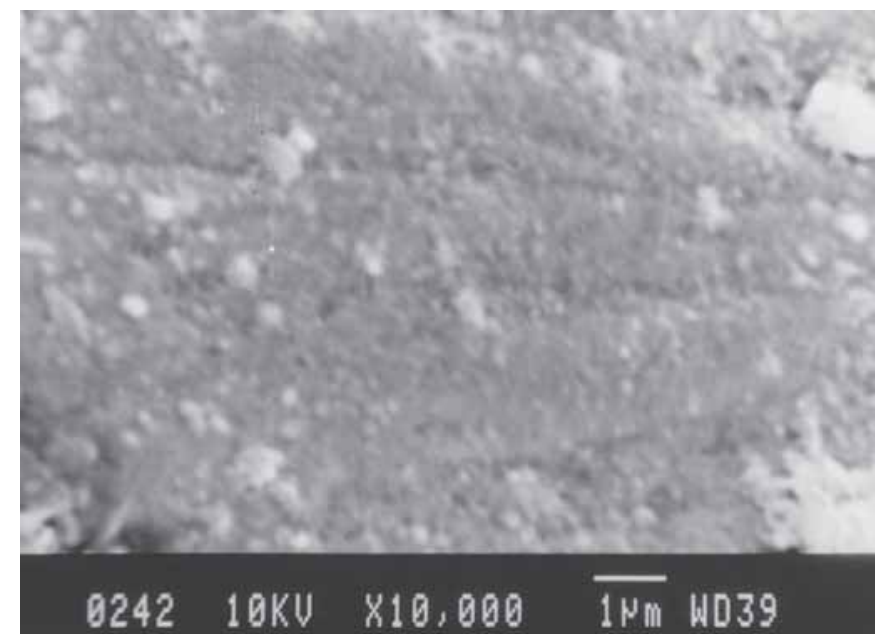

Fig. 12: Tooth surface exposed to new Mclnnes bleaching agent for 15 minutes $(\times 10,000$ magnification)

In this present study the enamel surface was exposed to $10 \%$ carbamide peroxide gel for time of $15,30,60$ minutes, 24 and 30 hours (Graph 3).

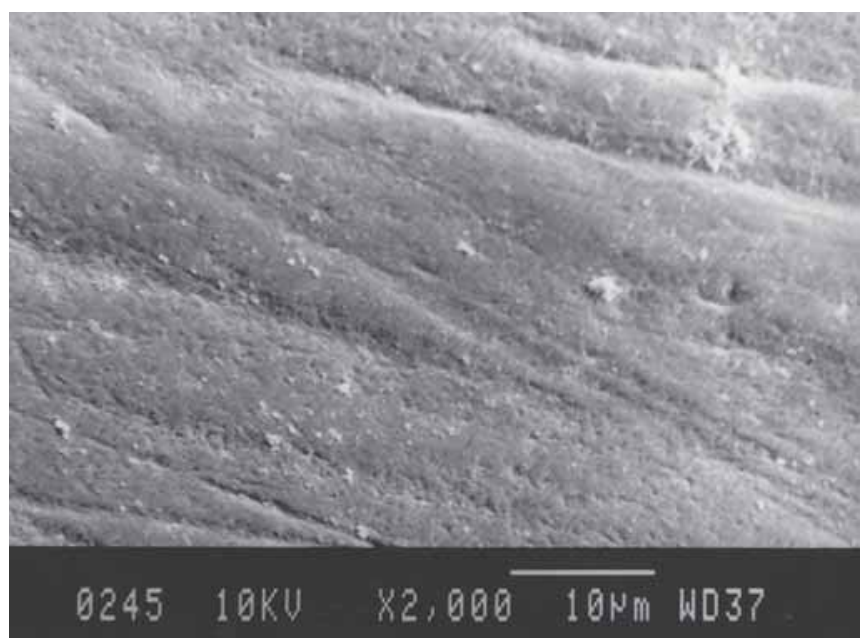

Fig. 13: Tooth surface control group II (×2000 magnification)

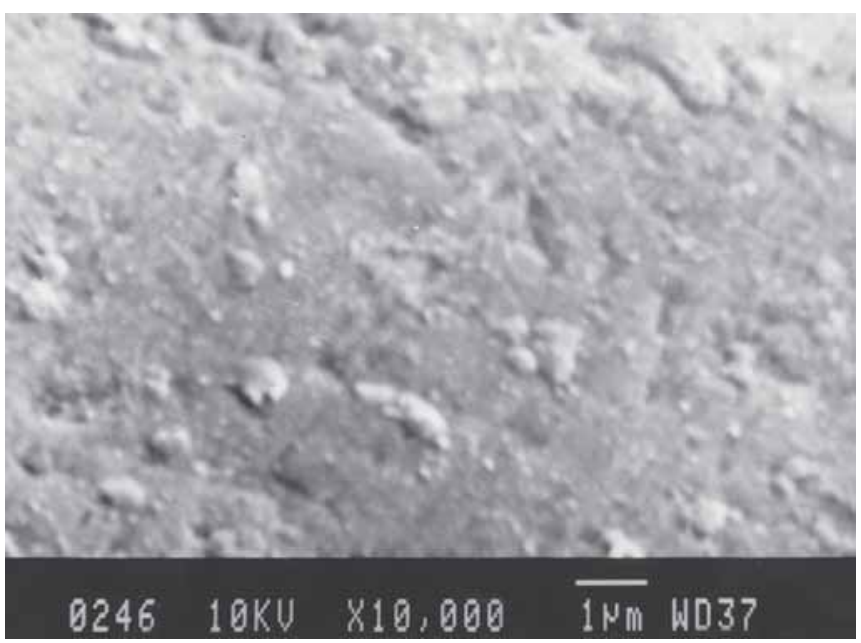

Fig. 14: Tooth surface subjected to new Mclnnes bleaching agent for 30 minutes ( $\times 10,000$ magnification).

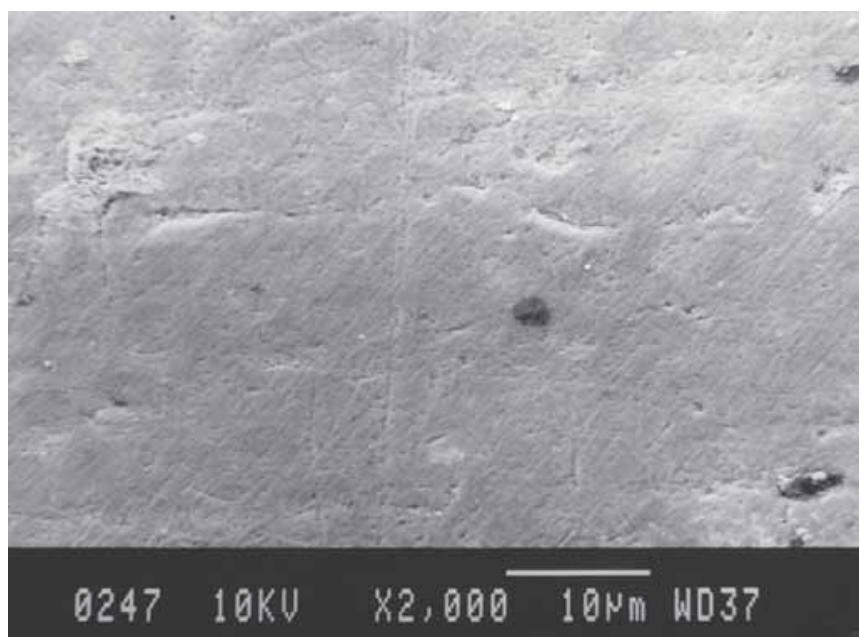

Fig. 15: Tooth surface control group II (×2000 magnification)

The carbamide peroxide bleaching gel cause mild-tomoderate changes, which was more marked as the duration of exposure increased (Figs 22 to 31). 


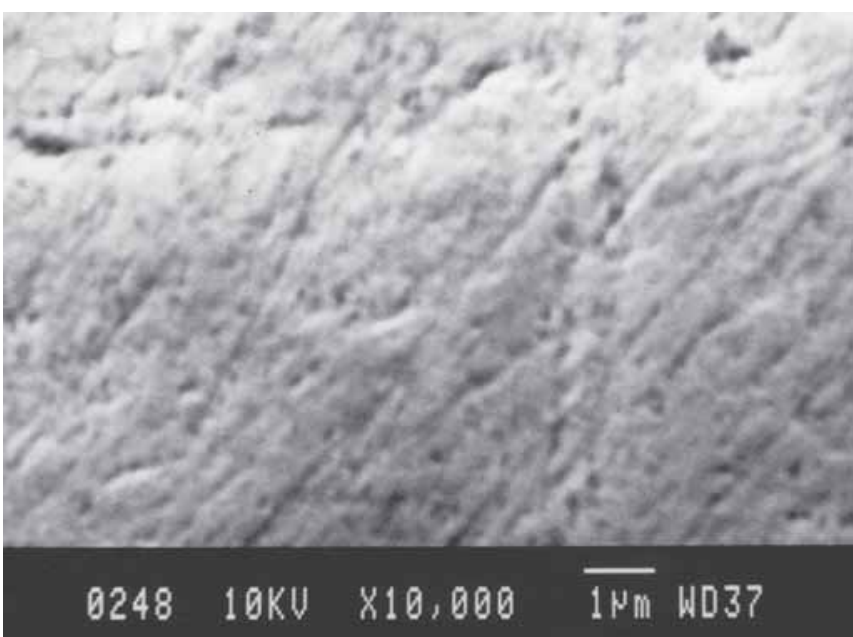

Fig. 16: Tooth surface subjected to new Mclnnes bleaching agent for 60 minutes $(\times 10,000$ magnification)

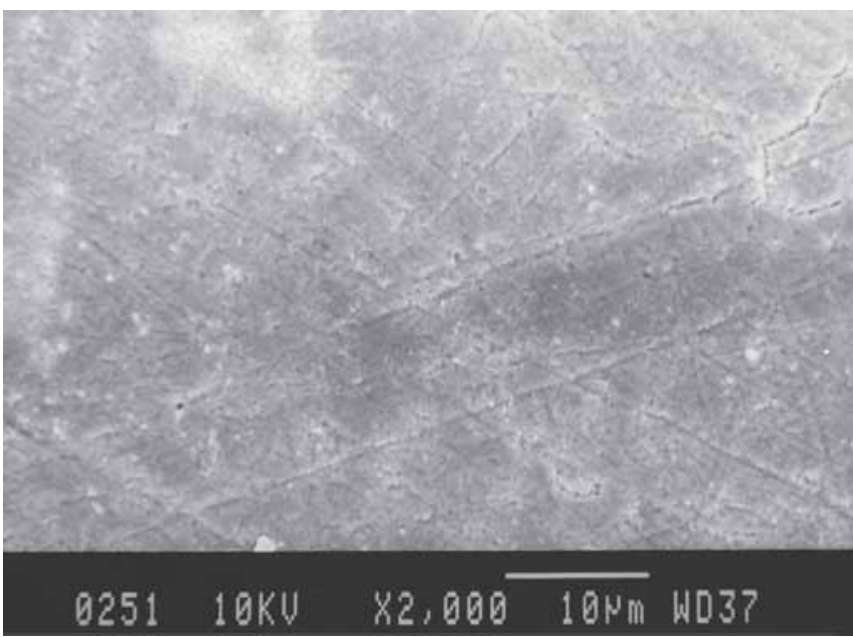

Fig. 17: Tooth surface control group II (×2000 magnification)

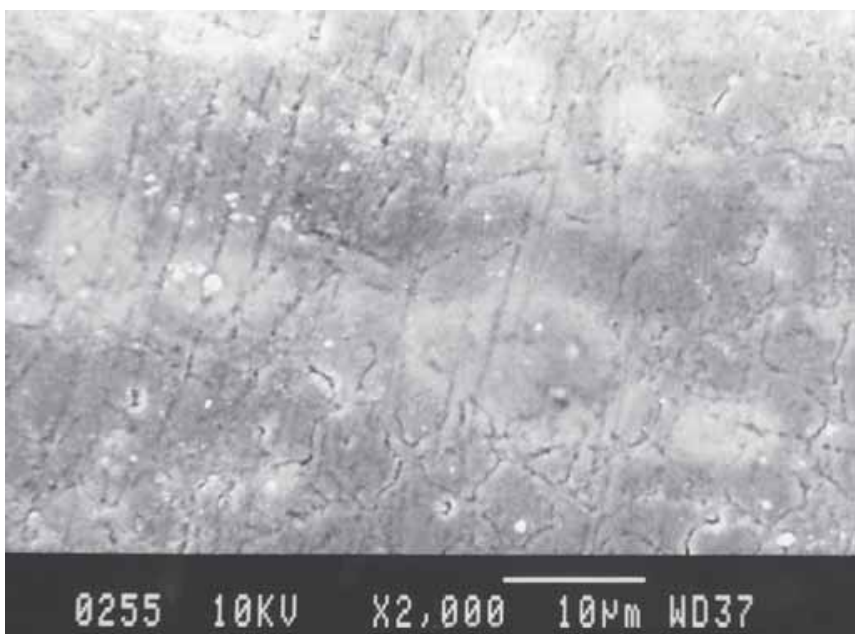

Fig. 18: Tooth surface subjected to new Mclnnes bleaching agent for 24 hours $(\times 100,000$ magnification)

Researchers have studied the effect of carbamide peroxide on human enamel, though their conclusions varied.

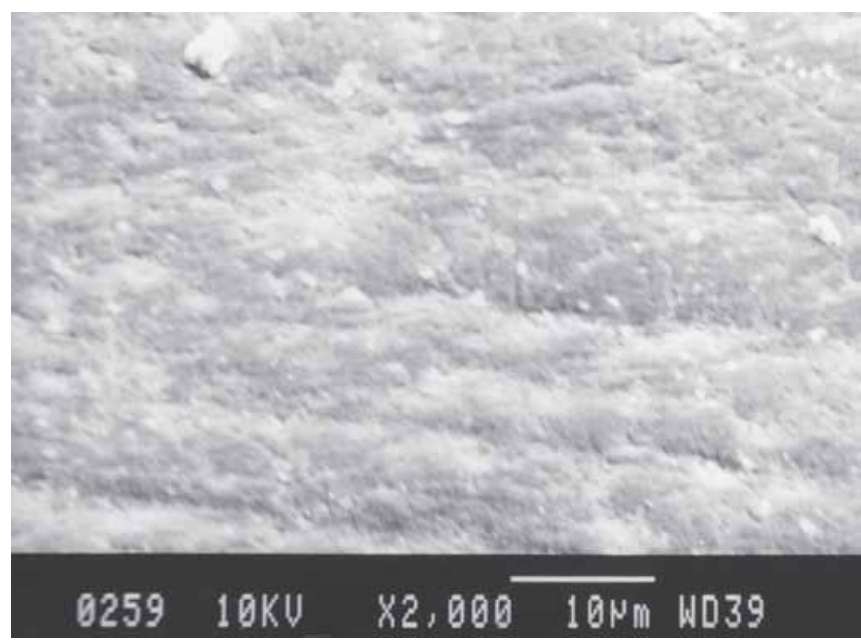

Fi g. 19: Tooth surface control group II (×2000 magnification)

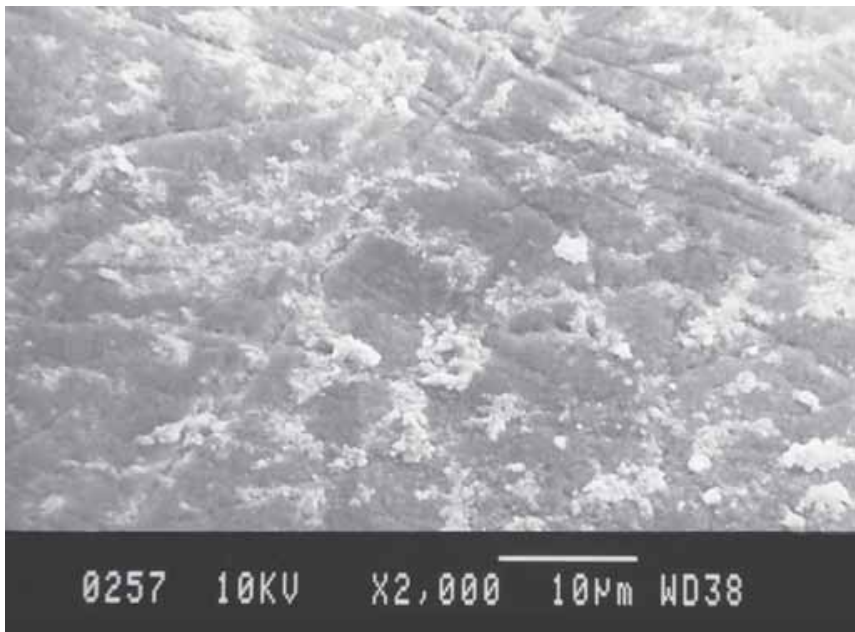

Fig. 20: Tooth surface exposed to new Mclnnes bleaching agent for 30 hours ( $\times 2000$ magnification)

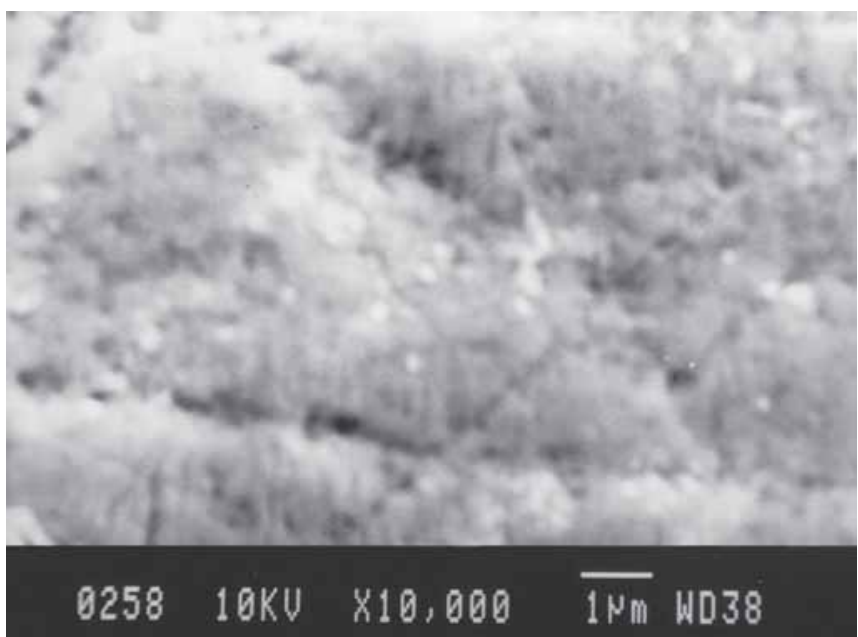

Fig. 21: Tooth surface exposed to new Mclnnes bleaching agent for 30 hours $(\times 10,000$ magnification)

Haywood et al showed no changes in surface morphology of human enamel outside that of normal variations using SEM evaluations in two studies. ${ }^{29}$ 


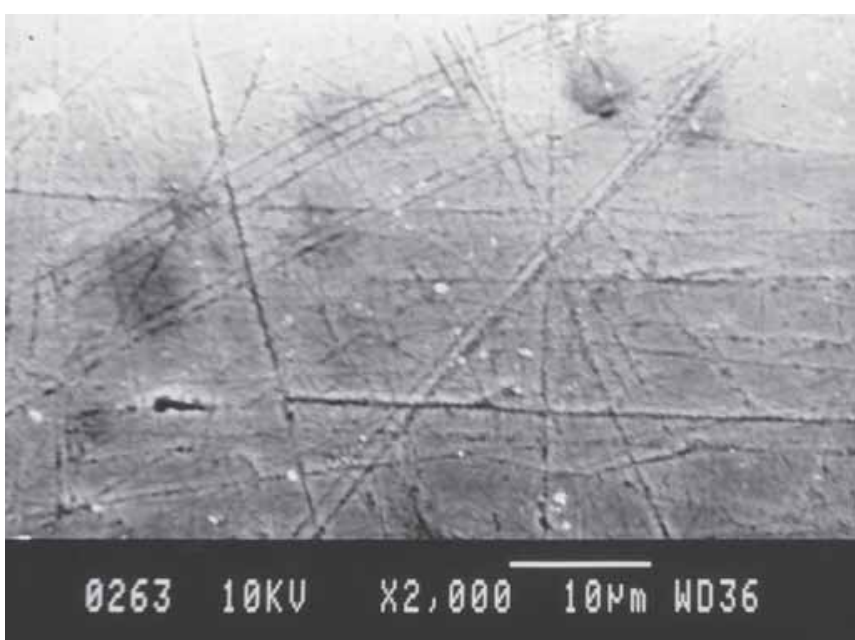

Fig. 22: Tooth surface control group III (×2000 magnification )

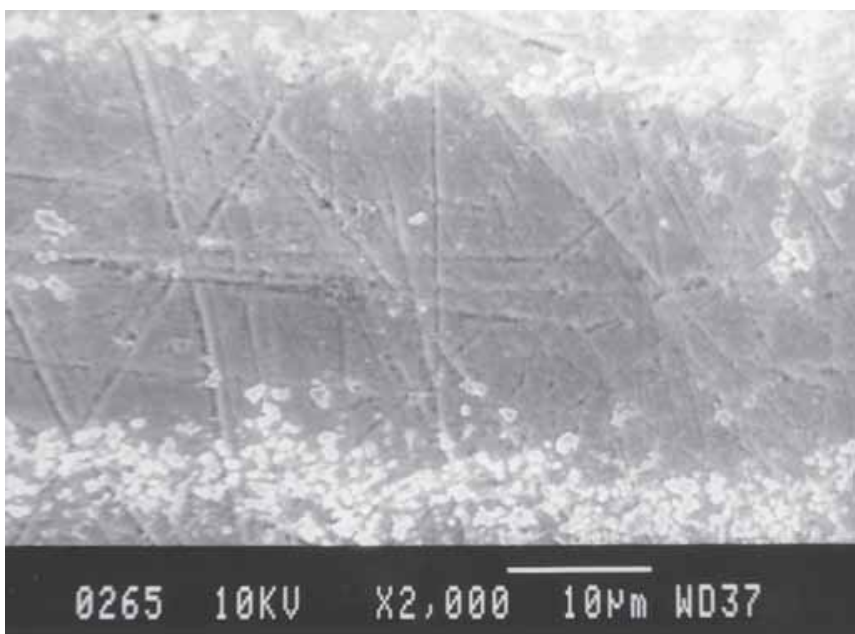

Fig. 23: Tooth surface subjected to $10 \%$ carbamide peroxide gel for 15 minutes ( $\times 2000$ magnification)

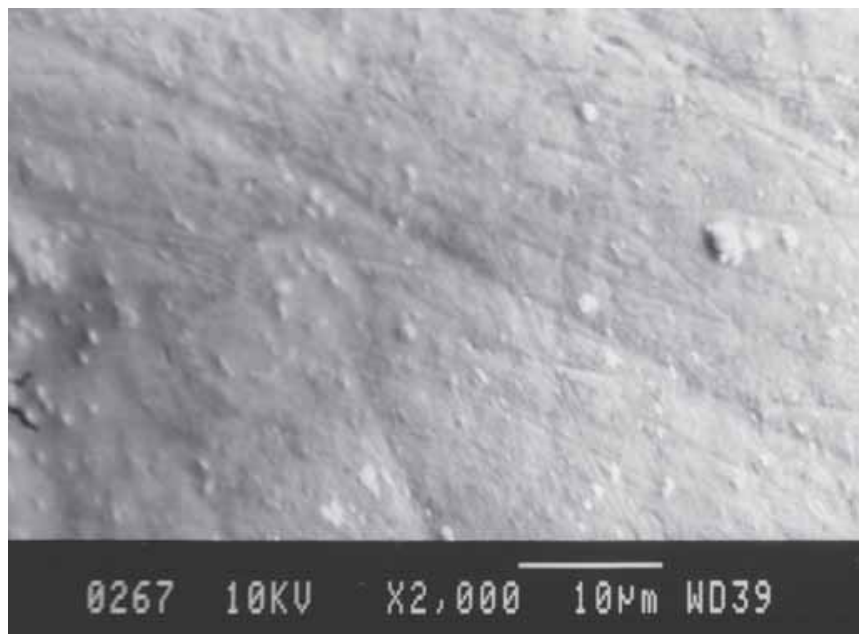

Fig. 24: Tooth surface control group III (×2000 magnification)

Shannon et al demonstrated slight morphological changes using SEM analysis. Covington et al reported changes in surface morphology utilizing SEM analysis, but did not find major changes in the composition of human analysis. ${ }^{30}$

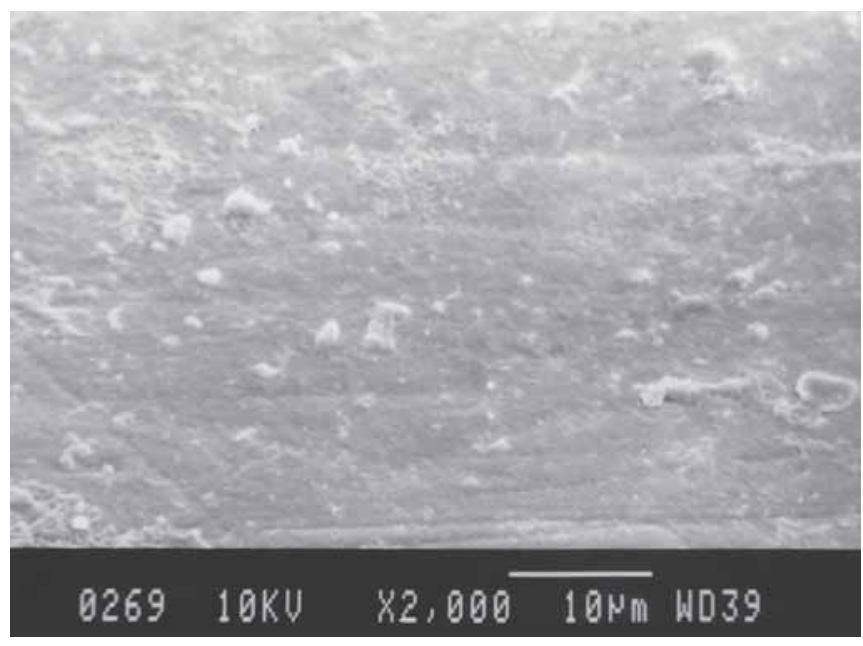

Fig. 25: Tooth surface subjected to $10 \%$ carbamide peroxide gel for 30 minutes ( $\times 2000$ magnification)

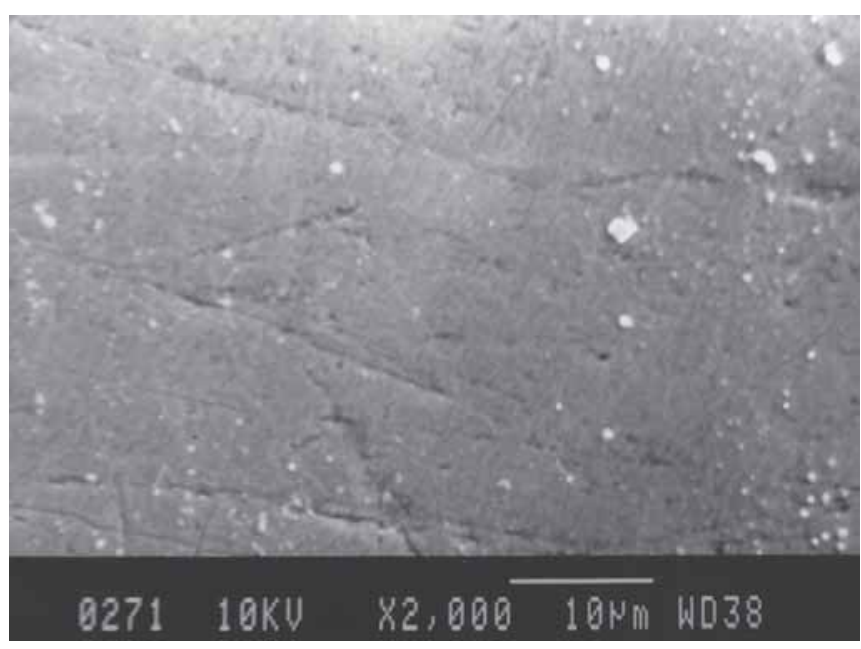

Fig. 26: Tooth surface control group III (×2000 magnification)

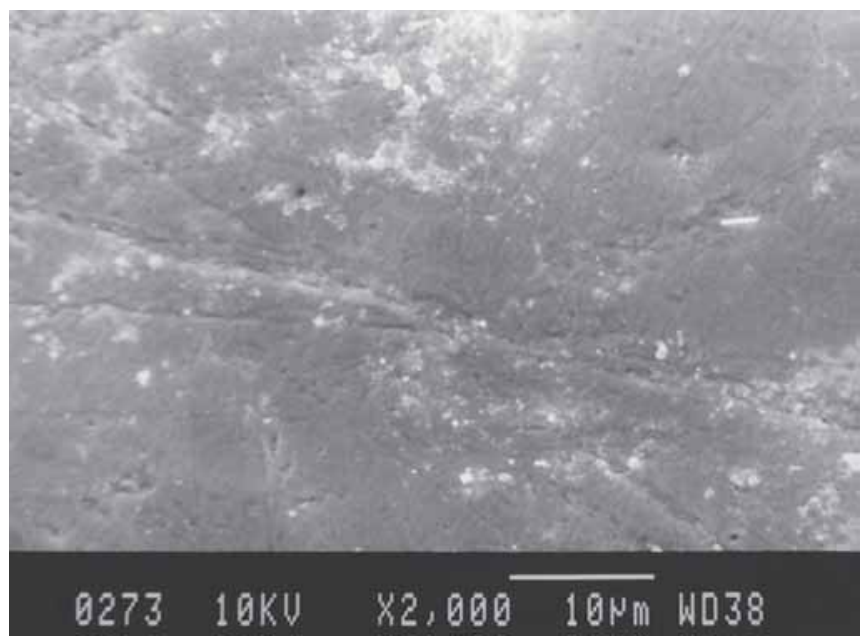

Fig. 27: Tooth surface subjected to $10 \%$ carbamide peroxide gel for 60 minutes ( $\times 2000$ magnification)

The observations in this present study is in agreement with the study of Bitter $\mathrm{CN}$ who evaluated the effect of carbamide peroxide bleaching agent on the enamel surface and observed alterations of direct relation to length of time 


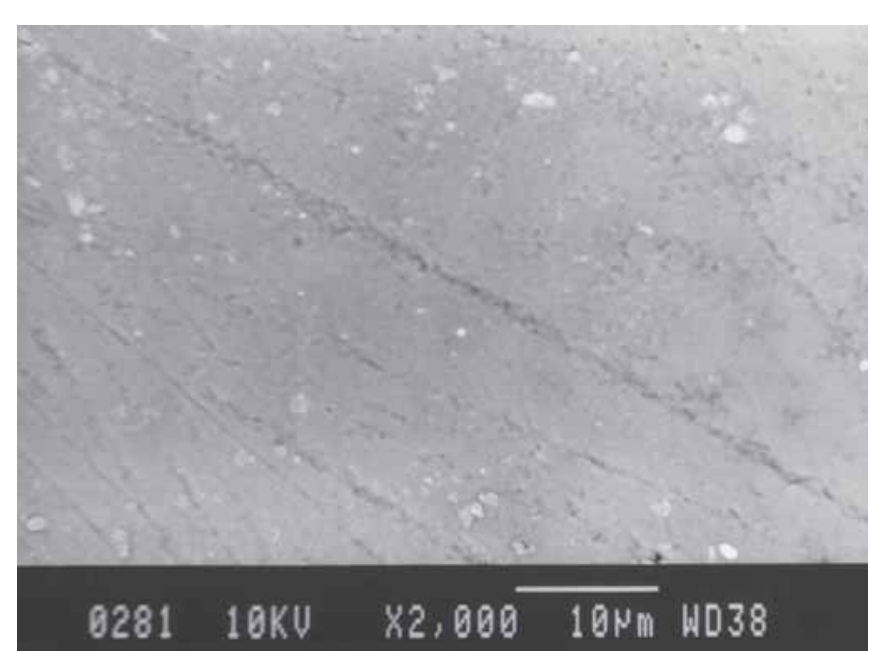

Fig. 28: Tooth surface control group III (×2000 magnification)

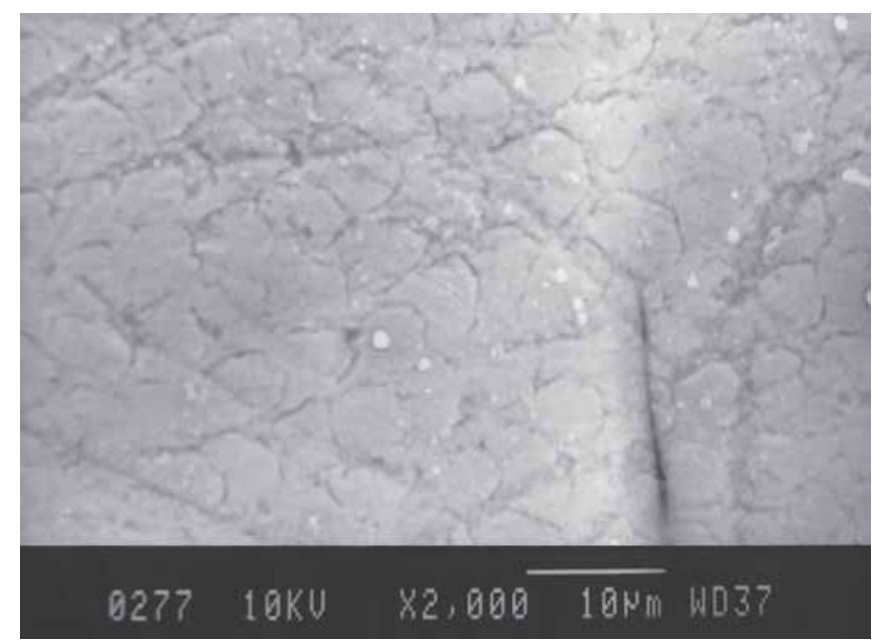

Fig. 29: Tooth surface subjected to $10 \%$ carbamide peroxide gel for 24 hours (×2000 magnification)

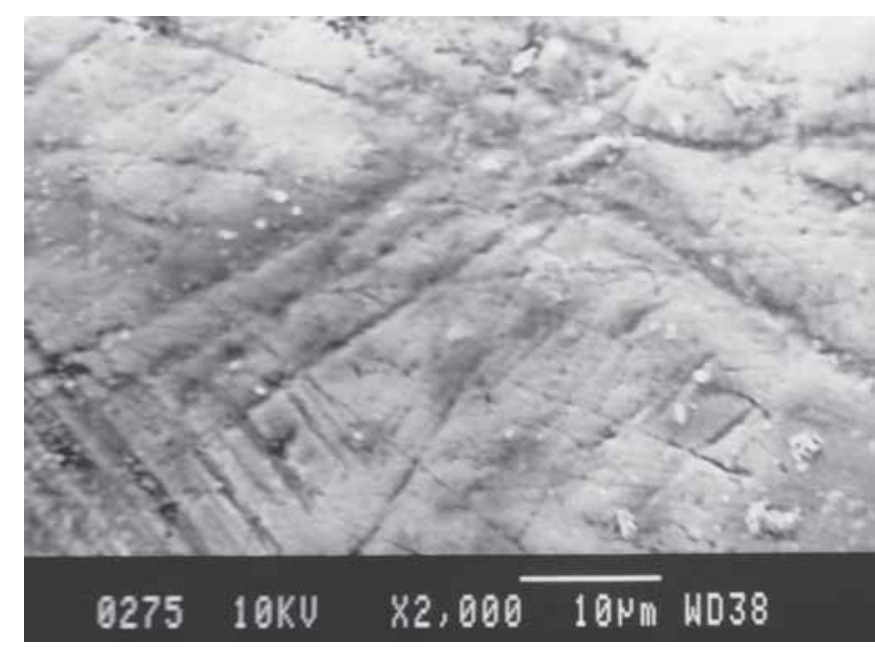

Fig. 30: Tooth surface control group III (×2000 magnification)

that the enamel surface was exposed to the bleaching agent. Ten percent carbamide peroxide bleaching agent ultimately breaks down into $3 \%$ hydrogen peroxide and $7 \%$ urea, it

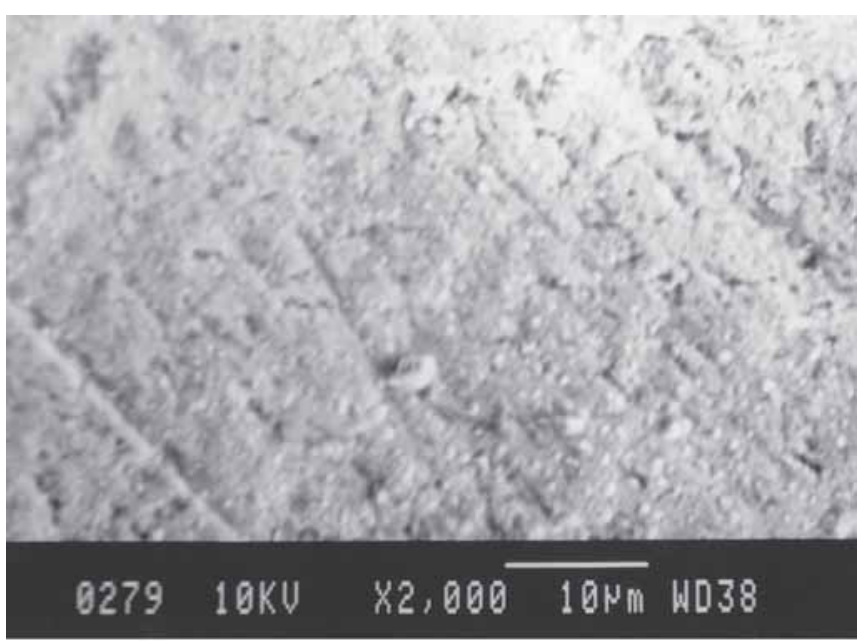

Fig. 31: Tooth surface subjected to $10 \%$ carbamide peroxide gel for 30 hours ( $\times 2000$ magnification)

has been shown that urea also moves freely through both enamel and dentin. Urea also has a low molecular weight $(64 \mathrm{~g} / \mathrm{mol})$.

Hayw ood and Haymann reported concern regarding the bleaching solution with a lower $\mathrm{pH}$, based on reports that the demineralization process of enamel begins when the $\mathrm{pH}$ falls below the critical pH of 5.2 to 5.8. However, no evidence of this process has been noted to date in any clinical trails or laboratory tests.

One explanation for this finding may be in the breakdown products of urea from carbamide peroxide. The ammonia and carbon dioxide released on degradation of the urea appears to have the effect of elevating the $\mathrm{pH}$.

Stephan reported that the application of urea raises the $\mathrm{pH}$ of plaque material, even in presence of carbohydrate to as high as 9.0. The absence of perceptible damage on the enamel surface when exposed to carbamide peroxide may be due to the oral conditions of the patient.

Tencate JM and Duijsters have shown that fluoride concentration of $2 \mathrm{ppm}$ at pH 4.5 is sufficient to effectively inhibit demineralization.

Therefore the absence of perceptible damage to the enamel may be to be related to the fact that:

1. The $\mathrm{pH}$ of the carbamide peroxide bleaching solutions rises rapidly upon exposure to oral fluids and is related to the concentration of urea that is present.

2. Demineralization is inhibited by the fluoride concentration in the tooth.

$M$ ore recent studies conducted at the $U$ niversity of N orth Carolina have shown no indication of either etching or significant change in surface morphology of enamel when evaluated under scanning electron microscope at magnification of x100, x200, x1000 and x4000 after 6 weeks treatment with various bleaching agents. These included 
the $10 \%$ carbamide peroxide preparations and hydrogen peroxide containing preparations.

The present study is in agreement with the above observations, in relation to new $\mathrm{M} c \mathrm{cl}$ nnes bleaching agent and carbamide peroxide gel, which did not produce any significant damage to the enamel.

\section{CONCLUSION}

The following conclusions can be drawn from the present study:

1. The dissolution and increased porosity of the enamel structure should be seriously considered when recommending the use of bleaching agents. The added effect of brushing in conjunction with the bleaching agents should also be weighed when considering their use.

2. The enamel surface subjected to remineral ization by oral fluids or whether its surface is renewed to form a new base of enamel prism structure is open to question and a worthy subject of further investigation.

\section{REFERENCES}

1. De F reitas PM, Turssi CP, Hara A T, Serra M C. M onitoring of demineralized dentin microhardness throughout and after bleaching. A m J Dent 2004;17:342-46.

2. M uraguchi K, Shigenobu S, Suzuki S, Tanaka T. Improvement of bonding to bleached bovine tooth surfaces by ascorbic acid treatment. Dent M ater J 2007;26:875-81.

3. Lai SC, M ak Y F, Cheung GS, et al. Reversal of compromised bonding to oxidized etched dentin. J Dent Res 2001;80: 1919-24.

4. Lai SC, Tay FR, Cheung GS, et al. Reversal of compromised bonding in bleached enamel. J Dent Res 2002;81:477-81.

5. Rodrigues JA, M archi GM, A mbrosano GM, Heymann HO, Pimenta LA . M icrohardness evaluation of in situ vital bleaching on human dental enamel using a novel study design. D ent $M$ ater 2005;21:1059-67.

6. Leonard RH, T eixeira EC, Garland GE, Ritter AV. Effect on enamel microhardness of two consumer-available bleaching solutions when compared with a dentist-prescribed, home applied bleaching solution and a control. J Esthet Restor Dent 2005; 17:343-50.

7. M urchison DF, Charlton DG, M oore BK. Carbamide peroxide bleaching: Effects on enamels surface hardness and bonding. Oper Dent 1992;17:181-85.

8. Seghi RR, Denry I. Effects of external bleaching on indentation and abrasion characteristics of human enamel in vitro. J Dent Res 1992;71:1340-44.

9. Sanches RP, Otani C, Damiao AJ, M iyakawa W. A F M characterization of bovine enamel and dentine after acid-etching. Micron 2009; 40:502-06.

10. De Oliveira R, Basting RT, Rodrigues JA, Rodrigues $A L$ jr, Serra MC. Effects of a carbamide peroxide agent and desensitizing dentifrices on enamel microhardness. A m J Dent 2003;16:42-46.

11. Haywood V B, L eech T, Heymann HO, Crumpler D, B ruggers K. N ightguard vital bleaching: Effects on enamel surface texture and diffusion. Quintessence Int 1990;21:801-04.

12. W hite DJ, K ozak K M , Zoladz J R, D uschner H, Gotz H. Peroxide interactions with hard tissues: Effects on surface hardness and surface/subsurface ultrastructural properties. Compend Contin Educ Dent 2002,23:42-48.

13. Polydorou $\mathrm{O}$, Hellwig $E$, Hahn $P$. The efficacy of three different in office bleaching systems and their effect on enamel microhardness. Oper Dent 2008;33:579-86.

14. Rodrigues JA, Erhardt MCG, M archi GM, Pimenta LAF, A mbrosano GM B . A ssociation effect of in-office and nightguard vital bleaching on dental enamel microhardness. Braz J Oral Sci 2002:365-69.

15. Lee CQ, Cobb CM, Zargartalebi F, Hu N. Effect of bleaching on microhardness, morphology, and color of enamel. Gen Dent 1995; 43:158-60.

16. Ferreira I, L opes GC, A raujo E, V ieira L CC, B aratieri L N. Effect of hydrogen peroxide based home bleaching agents on enamel hardness. B raz J Oral Sci 2006;5:1090-93.

17. Soldani P, A maral CM , Rodrigues J A. M icrol eakage evaluation of in situ vital bleaching and thicknening agents on human dental enamel. Int J Periodontics Restorative D ent 2010;30:203-11.

18. B roome JC. At-home use of $35 \%$ carbamide peroxide bleaching gel: A case report. Compend Contin Educ Dent 1998;19:824-29.

19. Leonard RH, Sharma A, Haywood VB. U se of different concentrations of carbamide peroxide for bleaching teeth: An in vitro study. Quintessence Int 1998;29:503-07.

20. Bitter NC. A scanning electron microscopy study of the effect of bleaching agents on enamel: a preliminary report. J Prosthet Dent 1992;67:852-55.

21. M cGuckin RS, Babin JF, M eyer BJ. A lterations in human enamel surface morphology following vital bleaching. J Prosthet Dent 1992;68:754-60.

22. Potocnik I, Kosec L, Gaspersic D. Effect of $10 \%$ carbamide peroxide bleaching gel on enamel microhardness, microstructure, and mineral content. J Endod 2000;26:203-06.

23. Berger SB, Cavalli V, A mbrosano GM, Giannini M. Changes in surface morphology and mineral ization level of human enamel following in-office bleaching with 35\% hydrogen peroxide and light irradiation. Gen Dent 2010;58:e74-79.

24. Fu B, Hoth-Hannig W, Hannig M. Effects of dental bleaching on micro- and nano-morphological alterations of the enamel surface. Am J Dent 2007;20:35-40.

25. Sturdevant JR. In: Roberson TM, Heymann HO, Swift J r EJ, (Eds). Sturdevant's A rt and Science of O perative Dentistry. St Louis, M osby Inc 2006;15-64.

26. Crews KM , Duncan D, Lentz D, G ordy F M , Tolbert B. Effect of bleaching agents on chemical composition of enamel. Mississippi Dental A ssociation Journal 1997;53(1):20-21.

27. Goldstein RE, Garber DA. Complete Dental Bleaching. Chicago Quintessence 1995;p 165.

28. M cCracken M S, Haywood VB. Effects of $10 \%$ carbamide peroxide on the subsurface hardness of enamel. Q uintessence International 2010;26(1):21-24.

29. M urchison DF, Charlton DG, M oore BK. Carbamide peroxide bleaching: Effects on enamel surface hardness and bonding. Operative Dentistry 2011;17(5):181-85. 
30. Rodrigues JA, B asting RT, Serra M C, Rodrigues A L J r. Effects of $10 \%$ carbamide peroxide bleaching on enamel microhardness. A merican J ournal of Dentistry 2003;14(2):67-71.

\section{ABOUT THE AUTHORS}

\section{AG Rajesh (Corresponding Author)}

Professor, Department of Conservative Dentistry and Endodontics RKDF Dental College and Research Centre, Hoshangabad B hopal, M adhya Pradesh, India, Phone: 9845075747, e-mail: denticsdentalcare@gmail.com

\section{LM Ranganath}

Professor, Department of Prosthodontics, RK DF D ental College and Research Centre, Bhopal, M adhya Pradesh, India

\section{KS Prem Kumar}

A ssociateProfessor, U Itra's B est D ental Science College and Hospital M adurai, Tamil Nadu, India

\section{B Sunil Rao}

Professor and Head, Department of Conservative Dentistry, B habha College of Dental Sciences, J hatkhedi, Hoshangabad Road, Bhopal $M$ ahdya Pradesh, India 